\title{
A literatura exposta em grito: a poetry slam ${ }^{1}$
}

\author{
The screaming literature: the poetry slam
}

\author{
Miriane da Costa Peregrino' (Universität Mannheim, Alemanha)
}

\begin{abstract}
Resumo: Este artigo apresenta notas etnográficas da pesquisa de campo realizada em Angola e Moçambique entre 2017 e 2018 por ocasião de intercâmbio nos centros culturais brasileiros nesses países e na Universidade Agostinho Neto, em Luanda. O contato com a poesia falada nesses países africanos de língua portuguesa resultou na investigação das raízes do poetry slam nos Estados Unidos e acabou por revelar uma aproximação com o Brasil, e igualmente com a Alemanha, o que aponta para um circuito literário que vem se construindo globalmente.

Palavras-chave: etnografia; poetry slam; Angola; Moçambique.
\end{abstract}

\begin{abstract}
This article presents ethnographic notes from field research carried out in Angola and Mozambique between 2017 and 2018, during exchange programs in Brazilian cultural centers in these countries and also at the Universidade Agostinho Neto, in Luanda. My contact with spoken poetry in these two Portuguese-speaking African countries resulted in the investigation of the roots of poetry slam in the United States, which ended up revealing an approximation with Brazil, and also with Germany, pointing to a literary circuit that is being built globally.
\end{abstract}

Keywords: ethnography; poetry slam; Angola; Mozambique.

\section{Apresentação}

Com o propósito de investigar as formas de produção e circulação da literatura angolana contemporânea, realizei um intercâmbio na Universidade Agostinho Neto, em Angola, entre 2017 e 2018. Foi no palco de um auditório fechado, localizado na Baixa de

\footnotetext{
${ }^{1} \mathrm{I}$ am indebted to the Baden-Württemberg Stiftung for the financial support of this research project by the Eliteprogramme for Postdocs.
} 
Luanda, que assisti à za Edição do Luanda Slam e reconheci, nas performances dos jovens artistas, as narrativas que expressam e traduzem a realidade e o cotidiano da cidade de Luanda nestas primeiras décadas do século XXI. Num segundo momento, regressei a Angola para atuar como coordenadora cultural do Centro Cultural do Brasil em Angola (CCBA), produzindo ali diversas atividades culturais, inclusive, a curadoria de eventos de poetry slam e spoken word e tive também a oportunidade de estender o intercâmbio até Moçambique, onde acabava de ser realizada a ıa Edição do Moz Slam.

O presente artigo apresenta notas etnográficas da pesquisa de campo realizada em Angola e Moçambique entre 2017 e 2018, por ocasião de intercâmbio nos centros culturais brasileiros nesses países e na Universidade Agostinho Neto, em Luanda. O contato com a poesia falada nesses países africanos de língua portuguesa resultou na investigação das raízes do poetry slam nos Estados Unidos e acabou por revelar uma aproximação com o Brasil e mesmo com a Alemanha, o que aponta para um circuito literário que vem se construindo globalmente. A pesquisa está em andamento; parte dela foi apresentada na tese de doutorado Luanda Slam: a literatura angolana fora da página, defendida em setembro de 2019, no Programa de Ciência da Literatura da Faculdade de Letras da Universidade Federal do Rio de Janeiro (UFRJ).

\section{Estados Unidos: de Chicago para o Mundo}

Era 1984. Eu comecei uma noite de poesias às segundas-feiras. O primeiro flyer dizia: 'Saia do caixão! Microfone aberto! Marc Smith, poeta norte-americano, o Slam Papi

O documentário Slam: voz de levante ${ }^{2}$ (2017) traz um panorama da poetry slam entre Estados Unidos, Brasil e França. Em dado momento, o poeta norte-americano Marc Smith lembra como era o cenário literário na década de 1980: "Tinha uma leitura de poesia por mês em Chicago. Era um grande evento e ninguém frequentava. E era um tédio. Muito elitista, esnobe" - conta Smith - "Se alguém estivesse num lugar onde ia acontecer uma leitura de poesia, a maioria das pessoas ia embora".

A imagem colorida do filme, que apresenta a sala onde conversavam o poeta norte-

\footnotetext{
${ }^{2}$ Documentário dirigido por Tatiana Lohman e Roberta Estrela D'Alva que percorre as cidades de Rio de Janeiro, Paris, Nova lorque, Chicago e São Paulo, apresentando a história e o contexto internacional da poetry slam.
} 
americano Marc Smith (1948-) e a artista brasileira Roberta Estrela D'Alva (1978-), desaparece e dá lugar a uma foto antiga de Marc, em preto e branco, enquanto o telespectador ainda pode ouvir sua narrativa em voz-off: "Era 1984. Eu comecei uma noite de poesias às segundas-feiras. O primeiro flyer dizia: 'Saia do caixão! Microfone aberto!"

O Uptown Poetry Slam tem lugar até hoje no Green Mill Jazz Club, um bar localizado num bairro branco e operário do norte de Chicago, Estados Unidos. Juntamente com o grupo Chicago Poetry Ensemble, Marc Smith criou o primeiro poetry slam do mundo. De forma simplificada podemos definir a poetry slam como uma competição de poesia falada. Tanto Roberta Estrela D'Alva (2011) quanto Cynthia Neves (2018) nos lembram que o termo "slam" é um empréstimo de práticas esportivas de beisebol, tênis e basquete, sentido que nos remete a uma "batida da poesia":

Foi nesse ambiente que o termo poetry slam foi cunhado, emprestando a terminologia "slam" dos torneios de beisebol e bridge, primeiramente para denominar as performances poéticas, e mais tarde as competições de poesia. Assim, em um fim de noite, de forma orgânica, e a partir de um jogo improvisado, o poetry slam nasceu. (D'ALVA, 2011, p. 120)

A palavra slam é uma onomatopeia da língua inglesa utilizada para indicar o som de uma "batida" de porta ou janela, seja esse movimento leve ou abrupto. Algo próximo do nosso "pá!" em língua portuguesa. (...) O termo slam é utilizado para se referir às finais de torneios de baseball, tênis, bridge, basquete, por exemplo. Smith nomeou também de slam os campeonatos de performances poéticas que organizava e no qual os slammers (poetas) eram avaliados com notas pelo público presente. (NEVES, 2018, p. 93)

Marc Kelly Smith, um operário branco da construção civil e poeta, mais do que um slammaster, aquele que conduz o show do slam, elaborou as regras da competição e ganhou o apelido de Slam Papi. Apesar disso, "nenhuma taxa precisa ser paga pela utilização do nome ou do método" slam (FREITAS, 2018, p. 94-95).

Segundo a pesquisadora Danielas Freitas, a poetry slam vem de uma extensa tradição de poesia falada nos Estados Unidos que remonta aos "readings dos poetas beatniks; do spoken words de poetas negros, como Gil Scott-Heron, que já gravavam seus LPs bem antes da existência dos MC's; da poesia de Langston Hughes com suas emulações dos ritmos do jazz", além do projeto de Walt Whitman "de alcançar o grande público através da poesia" (FREITAS, 2018, p. 94).

Muitas vezes, a prática de slam é confundida com a do spoken word. Um slam só acontece com a participação coletiva, com a formação de uma comunidade em torno da poesia enquanto o spoken word nasceu algumas décadas antes, e "se referia a textos 
gravados e difundidos pelo rádio", em especial, "com gêneros da música negra americana" como o hip-hop, e acabou sendo muito difundido nos anos go com o surgimento dos slams'. Segundo Estrela D'Alva, fazer spoken word não é o mesmo que fazer poetry slam (D'ALVA, 2011, p. 121).

No slam, nessa comunidade formada em torno da poesia falada, a cena é formada pelo slammaster (apresentador do show), os slammers (poetas competidores), o júri (muitas vezes eleito a partir do corpo da própria plateia da noite) e o grande público. Outro elemento extremamente importante no slam é o local onde a comunidade se reúne, que varia de lugar para lugar. A Uptown Poetry Slam com Marc Smith, como já vimos, acontece desde 1984 em um bar de Chicago, um espaço fechado, privado. No Brasil, a ZAP! Zona Autônoma da Palavra, primeiro slam brasileiro, também se dá em espaço fechado, mas muitos outros slams ocorrem ao ar livre, em praças, num formato que nos remete à ágora da Antiga Grécia. Em Angola e Moçambique, os eventos mensais de poesia também ocorrem em espaços fechados - em centros culturais, restaurantes, bares, principalmente. $E$ as competições são em espaços fechados também, tanto nesses países quanto na França, onde ocorre a Copa Mundial de Poetry Slam, quando utilizam grandes auditórios ou salas para realizar os concursos.

O local interfere na forma como o slammer se apresenta. As condições do espaço, em certa medida, vão interferir na performance do artista. Por isso, mesmo um poema declamado várias vezes não é nunca o mesmo poema. O texto, cada vez que é apresentado, é atravessado pela fala, pelo corpo do artista; pelo espaço, pela plateia, pelas condições do ambiente.

Não podemos esquecer que a poetry slam também é herdeira da performance art dos anos 1960. Cada performance resignifica o texto. O slam também se expande progressivamente a partir de Nova lorque quando se aproxima da cultura hip-hop. Nesse sentido, não podemos perder de vista que a poetry slam é uma prática também diaspórica, também herdeira de diversas tradições orais que se reinventam na América.

A seguir, apresentaremos alguns aspectos sobre o papel da performance segundo a pesquisadora brasileira Leda Martins e do medievalista suiço, Paul Zumthor. Professora e pesquisadora de textualidade oral afro-brasileira, Leda Martins nos lembra que o corpo é um lugar de memória, onde não só se registra, mas se reelabora o texto de modo performático:

O termo performance, conforme Richard Schechner (1988:vi), é inclusivo, 
podendo a performance ser abordada tanto quanto um leque (ou ventilador) quanto uma rede. Como um leque inclui por aderência modal ritos, performances do cotidiano, umas familiares, atividades lúdicas, o teatro, a dança, processos do fazer artístico, assim como, dentre outras práticas, performances de grande magnitude. No leque, todas essas práticas, com seus modos próprios e convenções especificas, estão dispostos como ambientes não hierarquizados, numa paisagem horizontilínea, processando-se como um continuum (MARTINS, 2003, p. 65)

Daniela Freitas, retomando os estudos do pesquisador suiço e medievalista Paul Zumthor, afirma que "o oral se torna uma urgência atual, uma espécie de retorno forçado ou revanche da voz humana contra a tecnologia dos media; uma necessidade de desestabilizar o curso hegemônico da escrita nas sociedades ocidentais" (FREITAS, 2018, p. 100). Como D'Alva (2011) afirma, a "aurea" do slam é imediata, presente, ainda que a performance possa ser reproduzida e registrada em vídeo:

De acordo com Paul Zumthor (2007), a performance oral é também gestual, ritualística por excelência, exige a participação do corpo e pode se dar em "teatralidade" ou "espetacularidade", dependendo de sua percepção espacial. É daí que emana o prazer do texto (BARTHES, 2006), gozo da liberdade para quem lê (no caso do slam, para quem declama) com o corpo e para quem ouve com a alma. Ainda segundo Zumthor (2007), aquele que lê/declama em voz alta toca o outro pelas orelhas, e aquele que escuta é capturado pela melodia e pelo ritmo impressos no ato da leitura/declamação. Ao mesmo tempo em que nos lançamos ao outro que nos escuta, escutamos também a nós mesmos, ao nosso corpo, já que a voz, explica-nos o autor francês, é um corpo que se lança ao outro e retorna a si mesmo. A leitura/ declamação em voz alta implica, pois, corpo e alteridade: é endereçada ao outro, dinamizando língua/corpo e sujeito. Por isso Zumthor (2007) clama por uma poesia vocal, recitação que requer a presença constante do corpo, músculos, vísceras e sangue, lugar central e único modo vivo de comunicação poética - eis a performance. (FREITAS, 2018, p. 100)

Essa relação entre o slammer (locutor/falante) e seu leitor (interlocutor/ouvinte), tão direta e interativa, reforça a comunidade, mas ela deixa "as condições de recepção (a escuta) e de produção (do texto) todo tempo em jogo" e acabam sendo "determinantes para a construção do gênero discursivo/textual poético" (FREITAS, 2018, p. 101):

Com efeito, nas formas poéticas transmitidas pela voz (ainda que elas tenham sido previamente compostas por escrito), a autonomia relativa do texto, em relação à obra, diminui muito: podemos supor que, no extremo, o efeito textual desapareceria e que todo o lugar da obra se investiria dos elementos performanciais, não textuais, como a pessoa e jogo do intérprete, o auditório, as circunstâncias, o ambiente cultural e, em profundidade, as relações intersubjetivas, as relações entre a 
representação e o vivido. De todos os componentes da obra, uma poética escrita pode, em alguns casos, ser mais ou menos econômica; uma poética de voz não o pode jamais. (...) Estou particularmente convencido de que a ideia de performance deveria ser amplamente estendida; ela deveria englobar o conjunto de fatos que compreende, hoje em dia, a palavra recepção, mas relaciono-a (...) para uma percepção sensorial - um engajamento do corpo. (...) O termo e a ideia de performance tendem (...) a cobrir toda uma espécie de teatralidade: aí está um sinal. Toda "literatura" não é fundamentalmente teatro? (ZUMTHOR Apud FREITAS, 2018, p. 9910, grifos meus).

Além disso, em muitos casos, o slammer apresenta textos que fazem parte de sua vida íntima, privada que compartilha no palco público através da poetry slam. Como Roberta Estrela D'Alva afirma, é uma escrita de autor-representação que se expressa entre o texto, o oral e o visual. (D'ALVA, 2011). O leitor/ouvinte é cativado por um conjunto de ações do slammer/falante ao microfone.

Não podemos deixar de mencionar as regras do slam. O Slam Papi, Marc Smith, criou as regras da competição, mas estimula que elas "sejam adaptadas por cada slam, de acordo com a realidade" local (FREITAS, 2018, p. 95). Contudo, existem três regras que devem ser mantidas em qualquer concurso: 1) Os poemas devem ser de autoria do próprio poeta que vai apresentá-lo; 2) cada poema deve ter no máximo três minutos de duração; e 3) não devem ser utilizados adereços, nem acompanhamento musical.

O slammer inglês, David Lee Morgan, afirma que existe uma nova regra no slam: "O calor da reação da plateia":

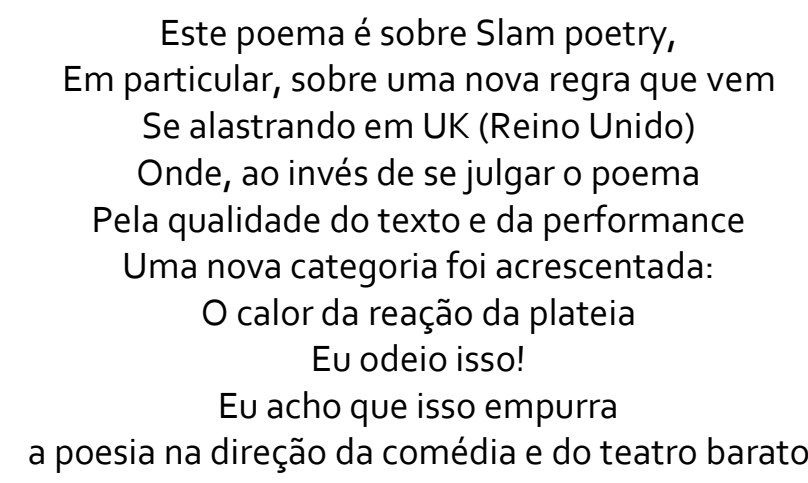

Antes de voltarmos ao ponto de crítica de Morgan, considero importante falar do poema em si. O exercício de metalinguagem que David Lee Morgan apresenta com seu poema foi filmado no documentário Slam: voz de levante (2017) durante a Copa Mundial de Poetry Slam de 2011. Nos slams brasileiros não é comum um slammer apresentar um texto oral com esse tipo de conteúdo. Como a própria Roberta Estrela D'Alva frisa em Slam: voz 
de levante (2017), por aqui, há temas que se têm sobreposto a qualquer outro como, por exemplo, as questões feministas, raciais e lgbts. Segundo Estrela D'Alva, o lugar de destaque e fala desses temas é legítimo, mas, diante deles, outros temas também devem surgir no palco. Um poema de amor, por exemplo, como Roberta sugere no filme. É preciso manter a pluralidade do slam para que sua prática continue sendo a de um espaço democrático, onde qualquer tema possa ser exposto.

Em Angola, a pluralidade de temas também chamou muito a minha atenção quando assisti aos slams. Ao contrário dos slams que eu conhecia no Rio de Janeiro, em Luanda, numa mesma noite, num mesmo palco, vi subirem uma slammer que recitou um poema a favor do aborto e outra, em seguida, que recitou um poema contra. Ambas foram aplaudidas pela plateia, nenhuma foi vaiada. Vi essa pluralidade e liberdade em mais do que uma ocasião por lá e pareceu-me ser mais uma valorização do texto e da apresentação em si do que do conteúdo. No Brasil, o conteúdo tem se sobreposto ao texto e, às vezes, à performance.

Voltando à questão da interferência do público e das regras do slam, é preciso reconhecer que com esse formato competitivo, a poesia falada ganhou ares de prática esportiva e se distanciou ainda mais da poesia tradicional. O público como júri, dispensa autoridades literárias para qualificar o valor da poesia. É da plateia o poder de determinar o sucesso ou não de um poema:

Além de alimentar uma atmosfera contracultural e de disseminar a poesia em lugares não-convencionais, o slam se desenvolveu através do exercício de certos ideais democráticos em contraste a convenções acadêmicas exclusivistas. [...] Desde o começo, o poetry slam adotou uma política de portas abertas: qualquer um pode se inscrever para batalhar, e qualquer um no público está qualificado para julgar. [...] Tal ênfase no público como crítico se distingue dos eventos de leitura de poesia mais tradicionais, que celebram ou reverenciam autores previamente classificados como dignos de valor por autoridades literárias. O poetry slam foi fundado sobre as premissas de que o poeta deve convencer o público a ouvi-lo, que qualquer um pode julgar uma competição e que a competição deve ser aberta a todas as pessoas e todas as formas de poesia. Slam poetry é verso que, pelo menos em teoria, pode ser acessado por qualquer um e cujo valor qualquer um pode determinar. A acessibilidade da slam poetry é facilitada e talvez exigida pela linguagem da performance, que se submete ao tempo e o espaço, e - talvez mais importante - à atenção da plateia. Em competições de slam nacionalmente certificadas, os poetas têm uma janela de no máximo três minutos, que, como o poeta e showman Bob Holman aponta, é exatamente a duração de uma canção popular. (SOMERS-WILLET Apud FREITAS, 2018, p. 95) 
Mas é possível julgar um poema? Volta e meia algum slammaster retoma esse questionamento: julga-se o poema? O poeta compete? Independentemente da resposta, o fato é que com esses ingredientes, a ideia de Marc Smith de dinamizar e popularizar a poesia falada, tornando-a mais atrativa para o público e menos acadêmica, tem sido bem sucedida. A primeira competição nacional dos EUA ocorreu na década de 1990, quase dez anos depois da criação do Uptown Poetry Slam em Chicago.

É a partir da década de 2000 que a prática da poetry slam se tem espalhado e tem conquistado adeptos por diversos lugares do mundo, atravessando fronteiras geográficas, econômicas, linguísticas, culturais, sociais, políticas, hibridizando-se às culturas locais. $\mathrm{Na}$ presente pesquisa, parto do princípio de que a expansão da poetry slam e a sua adesão, por uma juventude mundial diversa e urbana em vários pontos do mundo, se explica através de pelo menos quatro aspectos fundamentais: 1) sua associação à cultura hip hop; 2) o processo de globalização e homogeneização cultural a partir dos Estados Unidos; 3) as condições econômicas da comunidade que se une em torno do slam e 4) a oralidade que aproxima todas as culturas, uma vez que é uma marca que atravessa a ancestralidade de todos os povos.

Afinal, como a poetry slam sai de um bairro branco e operário de Chicago, se espalha pelos Estados Unidos e progressivamente chega até países tão diferentes entre si: França, Alemanha, Singapura, Madagascar e México, por exemplo? Para nosso estudo é pertinente apresentar a forma como a poetry slam conquista Angola, Moçambique e Brasil, exatamente nesta ordem, porque esse foi o meu percurso até encontrar a poetry slam como objeto de pesquisa.

\section{Angola: do Artes ao Vivo ao Luanda Slam}

Na Flup eu vi que era importante sim a gente trazer o elemento da competição para potencializar o movimento [de spoken word] em Angola. Elisângela Rita, criadora do Luanda Slam

Em 2004, Lukeny Bamba Fortunato, regressando dos Estados Unidos, protagonizou a criação do evento de microfone aberto denominado Artes ao Vivo. Caracterizado pela diversidade de apresentações - música, poesia, teatro, exibição de filmes -, o Artes ao Vivo recebeu em seu palco os mais diversos artistas nacionais e internacionais, anônimos e 
renomados, como, por exemplo, o rapper Luaty Beirão que já naquela época expressava sua insatisfação com o governo angolano.

Os componentes do núcleo de organização do evento foram mudando ao longo dos seus 15 anos de existência, estando sempre à frente o jovem rapper e produtor cultural, Lukeny Bamba Fortunato. Filho da elite nascente da pós-independência, Fortunato estudou na África do Sul antes de ingressar numa graduação em Administração nos Estados Unidos - curso que abandonou para se dedicar à música. Retornando a Angola, ele criou o evento que se tornou o principal palco da capital angolana para expressão de novos artistas e ideias. Cinco anos depois, concomitante ao evento Artes ao Vivo, Fortunato iniciou o programa de rádio Eclético FM, especialmente voltado para a cultura hip hop.

Em meados de 2011, aquela que viria a ser uma das principais vozes femininas e feministas em Angola, Elisângela Rita, juntou-se à organização do Artes ao Vivo. Assim como Fortunato, Elisângela Rita pertence à elite angolana: fez o ensino médio e frequentou a faculdade de direito na África do Sul e, recentemente, concluiu o mestrado em relações internacionais nos Estados Unidos. Tendo concluído ambos os cursos, Elisângela Rita passou a exercer a profissão na área de advocacia em Luanda enquanto, paralelamente, declama suas poesias e inicia suas atividades como produtora cultural na cena alternativa angolana.

Em 2013, quando o Goethe Institut de Angola - instituto cultural alemão em Luanda - promoveu o primeiro concurso de spoken word, The Spoken Word Project, Elisângela conquistou o segundo lugar e isso abriu portas para que ela fosse representar Angola na Festa Literária das Periferias (FLUPP) no Rio de Janeiro, no ano seguinte. Retornando da FLUPP, e do contato com o slam brasileiro, Elisângela Rita criou a primeira competição de slam de Angola: o Luanda Slam que está em sua $5^{\text {a }}$ edição. Desde então, saiu daí um(a) slammer para representar Angola na competição internacional Rio Poetry Slam da FLUPP, no Rio de Janeiro. "O fator decisivo foi mesmo ter ido à FLUPP e ter entendido que eram pessoas normais que organizavam um concurso tão grande", afirmou Elisângela Rita, acrescentando que "o que parecia muito distante, impossível e que eu não iria conseguir, na FLUPP entendi que não era bem assim. Pessoas normais, que também tinham outros trabalhos, pessoas como eu estavam a fazer uma FLUPP, então, eu também conseguiria realizar algo do gênero".

Em 2017, pouco antes da realização da $3^{a}$ edição do Luanda Slam, Elisângela Rita 
criou mais um evento, o Muhatu, o primeiro concurso de poesia feminina em Luanda, com o objetivo de promover e incentivar a participação de mulheres na cena do spoken word angolano.

O Artes ao Vivo é um evento semanal, realizados às terças-feiras, às 19h, e gratuito, mas os espaços que o abrigaram aos poucos foram pressionando a organização de modo a ter cobrança de ingressos. Em 19 de abril de 2019, o Artes ao Vivo completou 15 anos e voltou a ser realizado num dos restaurantes mais caros da orla de Luanda, o Espaço Bahia que fica na Avenida 4 de fevereiro - a Marginal -, próxima da Fortaleza de São Miguel. Pela primeira vez, o evento foi anunciado com cobrança de ingresso no valor de $1.000,00$ kwanzas (o que atualmente equivale a 12 reais), mas não teve a adesão de público e voltou a ser gratuito. Já os concursos de slam organizados por Rita são anuais e têm cobrança de entrada desde a primeira edição. Ambos, no entanto, são realizados em espaços fechados na baixa da cidade de Luanda.

Neste início do século XXI, Lukeny Bamba Fortunato e Elisângela Rita figuram entre os principais produtores culturais da cena urbana alternativa de Luanda; muito embora ambos pertençam à elite angolana, os eventos que inauguraram têm forte adesão das camadas mais populares da cidade, especialmente, dos moradores da periferia.

Antes de prosseguir na descrição e análise desses eventos é importante lembrar que há outros eventos e grupos literários em Angola. Destacamos aqui o Movimento Lev'Arte criado pelo escritor Kardo Bestilo, que foi um dos co-fundadores do Artes ao Vivo. O Movimento Lev'Arte, no entanto, não se limita à cidade de Luanda. Existem núcleos do movimento em partes mais distantes da cidade, como Benfica e Cazenga e mesmo em outras províncias. Em julho de 2019, o Lev'Arte completou 13 anos. Dentre os eventos do Lev'Arte em Luanda, destacamos o Poesia Eu Vivo e o Poesia à Volta da Fogueira realizados, respectivamente, semanalmente e mensalmente. Em 2018, o jovem Kiaco Zambo, através da produtora Art Sem Letra, criou o Slam Tundavala que tem sido realizado anualmente também.

No período após a independência, o Movimento Popular de Libertação de Angola (MPLA) organizou atividades de poesia através das Brigadas da Juventude espalhadas em todo o país. Hoje, por conta de sua vinculação ao partido no poder desde a independência, o MPLA, as Brigadas da Juventude têm pouca credibilidade e, consequentemente, poucos adeptos, mas foi um importante espaço de revelação de novos poetas dos anos 80, como 
Lopito Feijó, por exemplo. Popularizada e acentuada ainda durante a luta anticolonial, a declamação de poesia é uma atividade com forte adesão da juventude angolana tanto ontem, como hoje.

\section{Moçambique: do Noites de Poesia ao Moz Slam}

Nós temos jovens que na verdade já faziam Poetry Slam muito antes da palavra 'slam' (arremessar ou jogar, no contexto das competições de poesia) existir. As pessoas já o faziam de maneira espontânea. Féling Capela, fundador do Noites de Poesia

Embora a presente pesquisa não seja um estudo comparado entre dois países africanos de língua portuguesa - Angola e Moçambique - considero importante incluir aspectos da produção dos eventos de poesia com os quais tive contato em novembro de 2018, durante uma estadia de 15 dias em Maputo, a capital moçambicana. Minha viagem a Maputo foi viabilizada pelo Centro Cultural Brasil-Moçambique (CCBM) da Embaixada do Brasil em Maputo para realização de atividades do meu projeto de incentivo à leitura Literatura Comunica!: a exposição "Da Maré ao Canindé, inspiração para as periferias" que organizei com o Museu da Maré, em 2014, e de duas sessões de rodas de leitura sobre obras da escritora afro-brasileira Carolina de Jesus.

Através das redes sociais, eu já tinha feito contato com o produtor cultural, Hamilton Chambela, e isso possibilitou que alguns slammers tomassem conhecimento do meu projeto e também da minha pesquisa de doutorado, que comparecessem à abertura da exposição e participassem das rodas de leitura que fiz no CCBM. Isso também facilitou o contato com eles para a realização de entrevistas sobre o Moz Slam no âmbito mais específico da minha pesquisa.

Neste período de estadia, entrevistei os produtores culturais e poetas Enia Lipanga e Hamilton Chambela, que me indicaram que também entrevistasse Féling Capela, além de 9 dos 12 participantes do concurso de Moz Slam de 2018: Lucia Tite, João Nguenhe, Lorna Telma Zita, Ema de Jesus, Daniela Mussagy, Antonio Magaia, Gonçalves Gonçalo, César Victorino e Eurosinanda Mussui.

Obviamente, a aproximação com Angola iniciada em 2015 através da comunidade angolana do conjunto de favelas da Maré e a pesquisa de campo em Luanda, entre 2017 e 
2018, possibilitaram uma imersão mais profunda na cena literária e no contato com os atores do nosso estudo, o que tornaria qualquer estudo comparativo com Moçambique muito desigual. $E$, por isso, reforçamos que nossa intenção aqui não é comparar, mas sim apresentar que identifiquei, também em Moçambique, a efervescência da modalidade do slam, ou como apontam reportagens sobre a cena da poetry slam, um retorno à poesia de combate, tão comum no período da guerra pela independência.

No Brasil, em Angola e em Moçambique, respectivamente, notamos que a produção do poetry slam transita entre o morro e o asfalto, entre a Luanda do asfalto e a Luanda dos musseques, entre a cidade de cimento e o bairro de lata em Maputo, mas as competições, no caso dos dois países africanos, têm sido realizadas em equipamentos culturais formais localizados em zonas centrais das capitais como, por exemplo, o Centro Cultural BrasilAngola, em Luanda, e o Centro Cultural Franco-Moçambicano, em Maputo, e com cobrança de ingresso.

Também da necessidade de criar um novo espaço que abrigasse novos poetas, nasceu em Moçambique, há cerca de quinze anos, a União Nacional do Escritores (UNE) em oposição à Associação dos Escritores Moçambicanos (AEMO). Um grupo de jovens criou então o evento de microfone aberto Noites de Poesia. Do grupo fundador, apenas Féling Capela permaneceu na produção do projeto, mantendo-o vivo ainda hoje.

Capela é casado, pai de duas filhas, e exerce atualmente a direção cultural do Centro Cultural Moçambicano Alemão (CCMA), em Maputo. Em entrevista, Capela afirmou não ter concluído a graduação em letras na Universidade Eduardo Mondlane e ser, sobretudo, um autodidata, representando Moçambique através do spoken word em mais de 15 países, incluindo o Brasil. Dos slams brasileiros, Capela tem proximidade e já se apresentou no Slam da Guilhermina, que nasceu na zona leste de São Paulo, em 2012, e ocorre às sextas-feiras próximo à rua Astroga, ao lado da estação de metrô.

Atualmente, Capela é o Embaixador de Moçambique de Poetry Slam, mas como ele não pôde ir para Chade na $1^{\text {a }}$ edição da Copa Africana de Poetry Slam e ainda não se tinha organizado nenhuma competição de slam no âmbito provincial ou nacional, Moçambique não teve representante na primeira Copa africana realizada em 2018. Entre 25 e 27 de julho de 2019, Féling Capela realizou o Festival Internacional Poetas D'Alma de Artes Performativas sob os auspícios do CCMA, tendo sido a angolana Elisângela Rita uma das convidadas. 
Em novembro de 2018, tive a oportunidade de acompanhar o $5^{\circ}$ aniversário de um outro grupo literário: o Palavras são Palavras criado pela escritora e produtora cultural, Enia Lipanga, também casada, mãe e estudante de jornalismo. Em entrevista, Enia afirmou que a pouca rotatividade de poetas no Noites de Poesia, organizado por Féling Capela, motivou a criação do Palavras são Palavras onde, qualquer pessoa pode recitar. Durante os dois primeiros anos, Lipanga produziu o evento sozinha até associar-se ao jovem Hamilton Chambela e criarem a produtora Palavras são Palavras LDA.

Partiu de Hamilton Chambela a produção do primeiro concurso de slam de Moçambique realizado em outubro de 2018 em Maputo, o Moz Slam. Desde maio de 2018, várias eliminatórias aconteceram antes da realização da final da competição em 27 de outubro daquele ano. Para última ronda, quatro finalistas: Lúcia Tite, João Nguenha, Lorna Telma Zita e Ema de Jesus. Três mulheres e um homem num primeiro concurso. A vencedora do concurso, Lúcia Tite, de 18 anos, representou Moçambique na Copa Mundial de Poetry Slam na França (maio) e no Rio Poetry Slam/FLUP no Brasil (outubro) em 2019.

Entre os slammeres entrevistados, a maioria afirmou ter iniciado o exercício da declamação ainda na escola, primária ou secundária, pois a prática de apresentação de poesias é recorrente nas atividades escolares de Moçambique. E isso chamou minha atenção, em particular, porque mais uma vez notamos uma herança de tradição oral que torna a proliferação da poetry slam mais fácil nesse território. Mas chamou a minha atenção também porque existem concursos de slam escolares nos Estados Unidos e na França. No Brasil, Emerson Alcalde, um dos poetas fundadores do Slam Guilhermina, criou igualmente um projeto de slam nas escolas paulistas, inspirado no modelo que conheceu quando esteve na Copa Mundial de Poetry Slam, em Paris. Em Angola, Lukeny Bamba Fortunato deseja implantar um projeto semelhante.

\section{Brasil: do Zap! ao Slam Maré Cheia}

Me dá um microfone na mão, um bastão, isso aqui é um instrumento de poder Roberta Estrela D'Alva, fundadora do ZAP! Curadora do Rio Poetry Slam e Slam BR

Claro que antes de ir para Angola eu já tinha assistido a uma competição de slam no 
Brasil. No Estado do Rio de Janeiro, onde nasci e moro, o slam multiplicou-se rapidamente nos últimos cinco anos. Mas aqui, nunca me interessei ou pensei no slam quanto objeto de análise e estudo. Para tal, sempre dei preferência à literatura impressa, publicada. No projeto de incentivo à leitura e literatura que realizo em escolas públicas, bibliotecas comunitárias e espaços populares, o Literatura Comunica! Faço o que chamo de pesquisaação a partir de autores periféricos publicados: Carolina de Jesus, Férrez, Paulo Lins, Conceição Evaristo, Repper Fiell, Giovane Martins, entre outros. Mas em Angola não encontrei nos jovens autores publicados o que eu procurava. E o que era? Algo que traduzisse o cenário atual luandense na literatura, narrado por outros protagonistas que não os consagrados escritores que lutaram no período de independência. Foi no Luanda Slam que vi as discussões que me interessam expostas, debatidas oral e performaticamente, fora da página de um livro ainda que, contraditoriamente, dentro de um espaço privado.

Angola fez com que me interessasse por slam e pela influência do Rio Poetry Slam da FLUP e do Slam da Guilhermina, respectivamente, em Angola e Moçambique, me conduziram ao slam brasileiro, afinal, Elisângela Rita decidiu criar o primeiro concurso de slam angolano depois de participar do Rio Poetry Slam da FLUP, ou seja, o slam brasileiro exerce influência sobre a produção de outros slams também. Antônio Paciência e Bel Neto vieram ao Rio de Janeiro representar Angola neste mesmo evento. Em Moçambique, Féling Capela me falou do seu intercâmbio com os poetas do Slam Guilhermina, em São Paulo. Dessa forma, quando voltei ao Rio de Janeiro em dezembro de 2018 , eu sabia que estava na hora de entender melhor o circuito de slam daqui, para entender como o Brasil atravessa Angola no que tange a esse circuito cultural também.

Atualmente denominada Festa Literária das Periferias, a FLUP teve sua primeira edição em 2012 sob o título "Festa Literária das UPPs" (FLUPP) numa referência direta às Unidades de Polícia Pacificadora instaladas progressivamente nas favelas cariocas desde 2008 pela Secretaria Estadual de Segurança do Governo do Estado do Rio de Janeiro. Os organizadores da FLUPP, os escritores Julio Ludemir e Écio Salles, renomearam o nome do evento em 2013. Ano emblemático de manifestações populares no Brasil. No dia 14 de julho de 2013, o pedreiro Amarildo Dias de Souza desapareceu após ser levado pela força de pacificação, a UPP, que ocupava a favela da Rocinha. Mais tarde, a morte do ajudante de pedreiro foi confirmada. O caso Amarildo teve grande repercussão nacional e tornou-se símbolo da luta contra os casos de abuso de autoridade e violência policial no Rio de Janeiro. 
Em 2014, já renomeada Festa Literária das Periferias, a Flup criou o primeiro slam internacional da América Latina, o Rio Poetry Slam com curadoria e apresentação da paulista Roberta Estrela D’Alva. Desde então já passaram pelo Rio Poetry Slam, representando Angola, os slammers Elisângela Rita, Antônio Paciência, Bel Neto, Ermi Panzo e Luana Bartholomeu. Bel Neto foi a angolana melhor classificada até hoje, obtendo o 30 lugar no Rio Poetry Slam de 2017.

O nome de Roberta na curadoria do Rio Poetry Slam não é aleatório. Atriz graduada pela Universidade de São Paulo (USP) e mestre em Comunicação e Semiótica pela PUC-SP, Roberta foi uma das fundadoras da primeira companhia de teatro hip-hop do Brasil. Em 2008, após um intercâmbio nos Estados Unidos, Roberta Estrela D'Alva fundou o ZAP! (Zona Autônoma da Palavra) junto ao Núcleo Bartolomeu de Depoimentos, no bairro de Pompeia, em São Paulo. Ela também foi a primeira slammer brasileira a participar da Copa do Mundo de Poetry Slam, realizada na França e conquistou o 30 lugar na competição de 2011. É também organizadora do Slam $\mathrm{Br}$ de onde saem os representantes do Brasil para a Copa Mundial na França. Seu documentário Slam: voz de levante (2017), co-dirigido com Tatiana Lohmann, foi lançado no Festival do Rio e ganhou o prêmio de melhor direção de documentário.

Em 2012, outro grupo de poetas criou o segundo slam organizado na cidade de São Paulo, o Slam da Guilhermina. Como já foi dito, o Slam da Guilhermina tem uma relação mais estreita com o Noites de Poesia organizado pelo Féling Capela em Moçambique. $\mathrm{O}$ Slam da Guilhermina acontece em praça pública, ao lado da estação de metrô GuilherminaEsperança e é gratuito. Os neologismos slampião e slampiã surgem do Manifesto do Slam da Guilhermina em que faz referência a Lampião e à Maria Bonita, personagens da nossa história do cangaço. Segundo Daniela Freitas (2018), os slammers da Guilhermina "se comparam aos cangaceiros nordestinos que desestabilizaram o sistema latifundiário e coronelista" (FREITAS, 2018, p. 102).

Mas de São Paulo, é o poeta Allan da Rosa, da periferia de Taboão da Serra, quem dialoga com o angolano Lukeny Bamba Fortunato, criador do Artes ao Vivo, no documentário Cartas para Angola (2011). Numa das passagens do filme, as duas margens do Atlântico são ligadas pela poesia de Allan da Rosa e Lukeny Bamba Fortunato, dois poetas que nunca se encontraram pessoalmente, mas que compartilham a força da poesia falada. "São Paulo de Piratininga, São Paulo de Luanda" - recita Allan da Rosa. Mais adiante, o 
documentário traz imagens de uma noite do Artes ao Vivo, então realizado no Espaço Bahia, um restaurante na Baixa da cidade de Luanda, e Fortunato fala sobre spoken word. Foi o único filme que localizei que registra o Artes ao Vivo e seu papel contestador. Ao microfone, Lukeny fala sobre inflação e lembra que um melão estava custando 105 dólares (o que equivaleria a 9.500,00 Kwanzas) num dos supermercados da cidade e isso devia ser uma preocupação de todos que vivem ali. Em seguida, um poeta, que não é identificado no filme, recita: "Eu penso que eles já vêm a nos melar há muito tempo. Eles nos melam desde o princípio. Eles nos melam desde que Diogo Cão aportou a foz do rio Zaire, desde que nos transformaram em produto". O filme, dirigido por Coraci Ruiz e Julio Matos traz ainda o diálogo entre diversos personagens de Brasil, Angola e Portugal, incluindo os escritores angolanos Ondjaki e Ana Paula Tavares.

Outro aspecto fundamental do slam brasileiro é que, ao contrário das batalhas de MC's marcadas pela presença masculina, o protagonismo do movimento é das mulheres, como ilustram os nomes de Roberta Estrela D'Alva, Mel Duarte, Luz Ribeiro, Mariana Félix e MC Martina, por exemplo.

No Rio de Janeiro, o slam chegou em 2013 com o professor Paulo Emilio Azevedo. Mas na favela da Maré, o primeiro evento com formato de slam foi criado apenas em março de 2019. No Curso de pré-vestibular da ong Centro de Estudos e Ações Solidárias da Maré (CPV/CEASM), onde fui educadora popular, colaborei na realização de alguns saraus literários antes de ir para o intercâmbio em Angola. Destaco aqui o IV Sarau do CPV, realizado em 18 de março de 2017, cujo tema foi "Sarau das Minas". A programação do Sarau das Minas foi, obviamente, dedicada às mulheres. MC Martina, que dois meses depois seria uma das fundadoras do Slam Laje no Complexo do Alemão, se apresentou nesse sarau. Eu também me apresentei, não como poeta, mas, sim, como educadora, realizando roda de leitura sobre mulheres escritoras.

Mas de nome slam, o primeiro realizado na favela da Maré nasceu em 19 de março de 2019, por um outro grupo de jovens moradores: Isadora Gran, Matheus de Araújo, Rejane Camelô e Thais Ayomide criaram o Slam Maré Cheia que desde então ocorre mensalmente em pontos diversos do conjunto de favelas que compõem a Maré (Video: https://www.facebook.com/slam.mare.cheia/videos/2290711514479650/). Maré Cheia faz referência não só ao nome do conjunto de favelas onde se realiza, Maré, mas também à música "Quando a Maré encher," do grupo pernambucano Nação Zumbi. 
O slam brasileiro nasceu em São Paulo e, aos poucos, vai ganhando outros estados do país. Exatamente, 11 anos se passaram desde a realização do ZAP! até o surgimento de um slam na favela da Maré, Rio de Janeiro. A Maré foi o local do Rio de Janeiro onde trabalhei entre 2013 e 2017. Antes do meu intercâmbio para Angola, o cenário literário da Maré era marcado por saraus como o do pré-vestibular comunitário e o da loja Roça Rio e ainda projetos de incentivo à leitura como o Literatura Comunica! e ações das bibliotecas comunitárias.

\section{Considerações Abertas}

Então, é a soberania da voz que comanda a festa do prazer do texto. Laura Cavalcante Padilha

Os quadros apresentados acima não tiveram por objetivo historicizar o percurso da poetry slam, mas, sim, trazer um breve panorama que aponta as condições locais para o surgimento das competições de poetry slam em diferentes contextos e países. Em comum, a literatura exposta em grito. As vozes de uma maioria periférica amplificadas pelo microfone aberto. O grito é dos periféricos da cidade, do mundo que, afirmam, que precisam se fazer escutar.

Como já vimos, a poetry slam nasceu na década de 1980, em Chicago, pelas mãos do poeta norte-americano Marc Smith e tem se espalhado globalmente. Podemos inferir que não por acaso, o poetry slam chegou à Angola pelas mãos de dois jovens que estudaram e residiram nos Estados Unidos, entre o final da década de 1990 e o início da de 2000: Lukeny Bamba Fortunato e Elisângela Rita, ambos reconhecidos apresentadores/slammasters angolanos.

Em Slam: voz de levante (2017), Roberta Estrela D'Alva afirma que a poetry slam tem um formato que funciona em qualquer lugar do mundo e que não pode ser apenas algo americano, ao que Bob Holman discorda: "Eu acho que é uma coisa americana, sim. Tudo se resume a competição, a capitalismo" - afirma Holman, que continua - "Soa particularmente americano para mim porque pega algo que é livre e belo, algo que não pode ser comprado ou vendido e transforma isso num grande circo".

Apesar da crescente expansão da poetry slam, ela não tem o mesmo alcance do hip hop. No Rio de Janeiro e no Brasil, a Poetry Slam ganha maior visibilidade depois da 1 a 
edição do Rio Poetry Slam, em 2014. Em Angola, ela se destaca depois da 1a edição do Luanda Slam, em 2015, sofrendo um novo impacto em 2018, quando Lukeny Bamba Fortunato passou a apresentar o Artes ao Vivo no formato de um programa da Televisão Pública de Angola (TPA). O Artes ao Vivo chega, como programa de TV, a um grande número de províncias e passa a atingir um número muito maior de jovens angolanos.

Já em Moçambique, a primeira competição de slam ocorreu em 2018; os finalistas que entrevistei em Maputo afirmaram que não conheciam a modalidade antes. Nunca tinham ouvido falar de slam. É importante frisar que, ao contrário de Luanda em que dois produtores culturais - Lukeny Bamba Fortunato e Elisângela Rita - tiveram contato com o spoken word e o slam em intercâmbio no Estados Unidos, Maputo não teve um precursor dessa manifestação artística nos mesmos moldes. Hamilton Chambela, organizador da competição de slam em Maputo - o Moz Slam que já nasce como competição nacional - é um jovem artista e produtor cultural, antenado com a cultura hip hop e articulado com redes internacionais no mundo virtual. Foi a partir do contato com as competições de slam de outros lugares, nas redes sociais, que ele decidiu criar uma competição em Moçambique, segundo os dados que tenho da entrevista realizada com Chambela. Na final da 1a edição do Moz Slam, em outubro de 2018, esteve presente o francês Patrick Binard, diretor e slammaster da Copa Mundial de Poetry Slam realizada anualmente em Paris. Desde outubro, Binard e Chambela acertaram a ida do primeiro lugar do Moz Slam para a competição mundial na França, em maio de 2019.

Quando Kevin Coval, diretor do Young Chicago Authors, afirma que o slam é uma pequena parte da história da cultura jovem mundial, ele está certo. A poetry slam não é tão conhecida quanto o hip hop. No entanto, a poetry slam produzida no Brasil e em Moçambique, até ao momento, traz um elemento pouco comum na cultura hip hop: o protagonismo da narrativa de mulheres.

A poetry slam é parte e constrói a cultura urbana contemporânea, reconfigurando os circuitos da poesia, estabelecendo novos itinerários, novos protagonistas, novas formas de produzir e narrar a literatura. A poetry slam carrega em si a combinação do oral, escrito e visual que estabelecem também uma nova forma de interação com o público. As redes sociais mais do que apenas divulgar eventos de slam, servem como base de dados e informações sobre competições, slammasters, slammers e os próprios textos orais, muitas vezes, viralizados em plafatormas de vídeo como o youtube. Ainda que a "aura" da 
performance literária não possa ser captada através do vídeo, como defende Roberta Estrela D'Alva (2011, p.121), a imagem em movimento permite uma difusão muito maior desse exercício poético.

A configuração da poetry slam entre o oral, o escrito e o visual marcam a reconfiguração e desestabilização da cultura escrita nas sociedades ocidentais. Daniela Freitas, retomando os estudos do medievalista Paul Zumthor, afirma que "o oral se torna uma urgência atual, uma espécie de retorno forçado ou revanche da voz humana contra a tecnologia dos media; uma necessidade de desestabilizar o curso hegemônico da escrita nas sociedades ocidentais" (FREITAS, 2018, p. 100).

Ao mesmo tempo que faz uso de novas linguagens e não escapa da comercialização das práticas culturais contemporâneas, a poetry slam tem como base a tradição oral e, não apenas como revanche da voz sobre a tecnologia ou a cultura escrita/publicada, é uma resposta ao isolamento do ser humano na sociedade moderna. O slam é, por excelência, sinônimo de encontro, de reunião, é uma prática literária que se faz em diálogo com o outro presencialmente. Acredito que aqui tenhamos conseguido pontuar a complexidade não só dessa prática literária, mas de sua expansão entre jovens em diversos países. Hoje, podemos afirmar que a poetry slam é um produto da emergência de culturas híbridas no qual tradição, tecnologia e pós-modernidade se encontram e se entrelaçam nessa prática discursiva.

\section{Bibliografia Citada}

BEIRÃO, Luaty. Sou eu mais livre, então - diário de um preso político angolano. Tinta da China: Portugal, 2016.

D'ALVA, Roberta Estrela. "Um microfone na mão e uma ideia na cabeça - o poetry slam entra em cena." Synergies Brésil, n. 9, 2011, pp. 119-126.

FREITAS, Daniela Silva de. Ensaios sobre o rap e o slam na São Paulo contemporânea. Tese (Doutorado) Departamento de Letras da Pontifíca Universidade Católica do Rio de Janeiro, 2018.

LÁZARO, Gilson \& SILVA, Osvaldo. Hip-hop em Angola: o rap de intervenção social. Caderno de Estudos Africanos da Universidade de Lisboa. Lisboa, 2016.

MARTINS, Leda. MARTINS, Leda. "Performances da oralitura." Revista Letras, n.26, 2003. Disponível em: https://periodicos.ufsm.br/letras/article/view/11881/7308. Acesso em 30 set 2019 . 
NEVES, Cynthia Agra. "Slams - Letramentos literários de reexistências ao/no mundo contemporâneo." Linha D'Água, São Paulo, v.30. n.2, outubro de 2017.

PADILHA, Laura Cavalcante. Entre voz e letra: o lugar da ancestralidade na ficção angolana do século XX. Niterói: EDUFF, Rio de Janeiro: Pallas Editora, 2007.

PEREGRINO, Miriane. Muhatu e a virada do spoken word em Angola. Mulemba. Rio de Janeiro: UFRJ, vol. 11, n. 21, p. 58-72, jul-dez 2019.

PEREGRINO, Miriane. Luanda Slam: a literatura angolana fora da página. Rio de Janeiro, 2019. Tese (Doutorado em Ciência da Literatura) - Faculdade de Letras, Universidade Federal do Rio de Janeiro, Rio de Janeiro, 2019. $241 \mathrm{f}$.

PEREGRINO, Miriane. "Slam Maré Cheia realiza batalha de poesia itinerante na favela da Maré." RioOnWatch, Rio de Janeiro, julho de 2019. Disponível em:

https://rioonwatch.org.br/?p=41568\&fbclid=IwAR2XLmIPZ2G8KSI6W1yb1ugWjhepE3VkM MxMJC7lx_rOoOrTJPMUpf6mVk. Acesso em: 27 set 2019.

SECCO, Carmen Lúcia Tindó. "A poesia angolana pós-independência: tendências e impasses." Revista Veredas da Associação Internacional de Lusitanistas, 2006.

SIMBAD, Helder." Do Spoken Word ao conceito de poesia dita." Jornal de Cultura. 24 jun 2016. Disponível em: http://jornalcultura.sapo.ao/letras/do-spoken-word-ao-conceito-depoesia-dita/fotos Acesso: 24 set 2019.

\section{Filmografia}

CARTAS para Angola. Direção de Coraci Ruiz e Júlio Matos. São Paulo: Laboratório Cisco, 2011. (75 $\mathrm{min}$ )

SLAM: Voz de Levante. Direção de Tatiana Lohmann e Roberta Estrela D'Dalva. Rio de Janeiro: Globo Filmes, 2017. (104 min)

HIP-HOP Evolution (Temporada 1-2). HBO Canadá/Netflix [Seriado]. Direção: Darby Wheeler, Canadá: Banger Films, 2016/2018.

\footnotetext{
${ }^{\mathrm{i}}$ Pós-Doutoranda, Universität Mannheim, Alemanha.

E-mail: miriane.peregrino@gmail.com
} 